\title{
Associate Editor Arved Weimann
}

We would like to introduce our new associate editor.

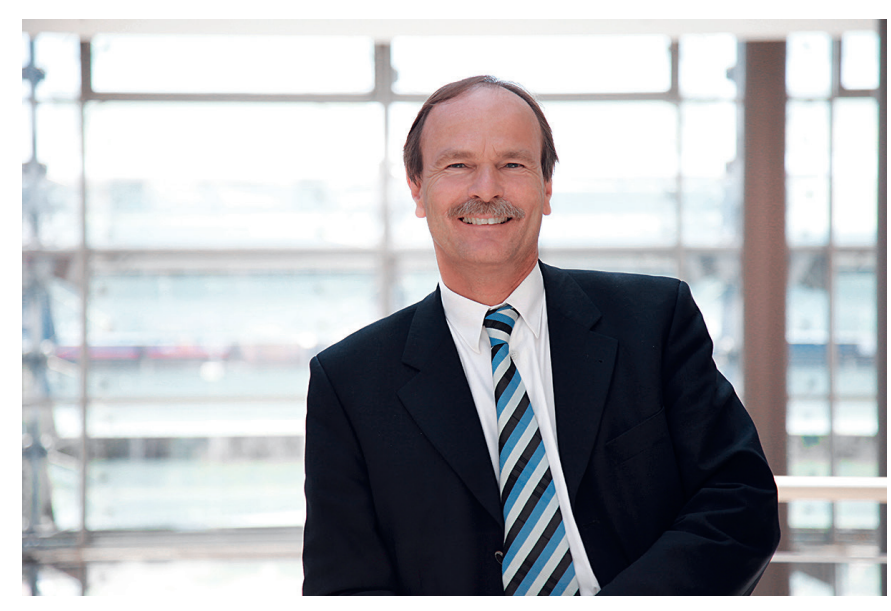

\section{Arved Weimann}

Chefarzt, Klinik für Allgemein-, Viszeral- und Onkologische Chirurgie, Klinikum St. Georg, Leipzig, Germany
Arved Weimann is Head of the Department for General and Visceral Surgery and Clinical Nutrition at St. George Hospital in Leipzig/Germany, and Assoc. Professor of Surgery at Hannover Medical School/Germany. Arved has a special interest in surgical metabolism and nutritional therapy in high-risk patients undergoing major abdominal surgery for cancer and those with critical illness. He has chaired the guideline working group surgery of the European Society for Clinical Nutrition and Metabolism (ESPEN) - update 2017. He holds a Master degree in Medical Ethics, and has published over 100 peer-reviewed articles in the field of perioperative nutrition and surgical oncology.

\section{KARGER}

(C) 2018 S. Karger AG, Basel

E-Mail karger@karger.com

www.karger.com/anm
Prof. Dr. med. Arved Weimann

Chefarzt, Klinik für Allgemein-, Viszeral- und Onkologische Chirurgie Klinikum St. Georg gGmbH

Delitzscher Straße 141, DE-04129 Leipzig (Germany)

E-Mail Arved.Weimann@ sanktgeorg.de 